\title{
Development of a Universal Position Interface, Applied for reliable and interactive access from distant locations to central database information through unambiguous position key in the construction industry. (UPIA)
}

\author{
Hans ten Brinke \\ Hollandse Beton Groep \\ P.O. Box 82, 2280 AB Rijswijk, The Netherlands \\ htbrinke@hbg-bvg.nl \\ (from 01-01-2004:) \\ Koninklijke BAM Groep \\ P.O. Box 20, 3980 CA Bunnik, The Netherlands
}

\begin{abstract}
To improve the availability of reliable information on an arbitrary location in or outside a construction project and to exchange information faster, more efficient and in an interactive way HBG developed the UPIA-device. With this handheld device location based information can be generated on site and can be used interactive by reliable and interactive access to a central database on a distant location. As a tool for quality monitoring the application is tested successfully at complex building projects.
\end{abstract}

KEYWORDS: GPS, INFORMATION MANAGEMENT, LOCATION RELATED DATA, PORTABLE COMPUTERS, POSITION INTERFACE, PRODUCT MODEL DATABASE, SUPPORT SYSTEMS FOR MONITORING.

\section{INTRODUCTION}

One of the problems the construction industry is facing is the need and urge for availability of reliable information on an arbitrary location in or outside construction projects all over the world. Beside this there's consensus of opinion that exchange of information should go faster, more efficient and in an interactive way to get the correct information, just in time in the right place.

In general, development and research is increasing in the area of mobile communication, developing applications for handheld computers and the use of positioning technology, for example in navigation systems by GPS. Hollandse Beton Groep (HBG) expects possibilities for optimising their processes and solutions for the described problems by introducing this technology in the company.

HBG is developing an application for the construction sector together with several European partners: Tensing SKS [NL], Tethys [NL], Becker
[D], VCS [D], IMST [D], and Egemin [B] ${ }^{1}$. These companies are mainly involved in development and consultancy in communication and positioning in aviation and satellites and in industrial automation solutions. HBG is contributing their specific constructors' knowledge.

This paper describes one of the promising developments regarding information and information management in the construction sector at HBG.

The next paragraphs describe what the UPIA-project involves; how it is introduced and developed on the construction site together with the building workers and what the results of the introduction of the application are.

\section{UPIA}

Communication conflicts, beside the increasing complexity of construction projects are causing

\footnotetext{
${ }^{1}$ Craft project: CRAF-1999-70547, EC-contractnr.: IST-2000-52034
} 
problems during construction. Delay and fail costs ${ }^{2}$ are results of for example misunderstanding and poor project insight ${ }^{3}$. From this point of view HBG participates the UPIA-project to support site monitoring activities, which require data access and storage to locations.

\subsection{Monitoring activities during construction}

During the construction process, several aspects are checked on site on a regular basis, per location. In the current process much data are manually reentered per quality or process check. Lack of structured data, use of electronic documents, use of handheld devices and the number of design changes disturb these monitoring processes. Mobile access to location related data is expected to support the monitoring process and to eliminate these disturbing factors.

\subsection{Data structuring, positioning and communication}

Mobile access to location related data first requires data structuring. Critical aspect is that a lot of data related to locations, spaces and levels, is processed during the project.

The status quo is that data in several documents are not related and interpretable for computers, spreadsheet programmes, 2D drawings containing lines and specifications in voluminous documents. The challenge is to utilize the application in combination with model based ICT solutions. These model based solutions enable to create and process 3D product models, from which consistent drawings can be derived and which provide an intelligent object oriented data structure for storage of 'all' product and process related data. In this way the 'Central Database' is realized.

UPIA Project-partners are developing a Universal Position Interface: a GPS-based device for indoor and outdoor positioning.

${ }^{2}$ Estimated between 2.5 and 5 billion Euros in the building construction sector in the Netherlands in the year 2000. [NRC, 05-23-2003 'Fouten in bouw kosten miljarden']

${ }^{3}$ SBR, 'De bouw moet om, op weg naar feilloos bouwen', 2000
Depending on the technology used for identification of a location, the need for interactive access to a central database sophisticated communication technology is required.

\section{PROCESS OF DEVELOPMENT}

To introduce this new 'high-technology' in what is often identified as a 'low-tech' sector requires a step by step development and approach of the development process. The choice was made to development an application which solved an 'existing problem', therefore close cooperation with building workers on site was crucial.

\subsection{Phase 1}

A stand alone Application was developed to support quality monitoring on site per space. Rooms were identified by scanning transponders and a laptop was used as handheld device. This solution was evaluated on a live project: Hotel Mercure.

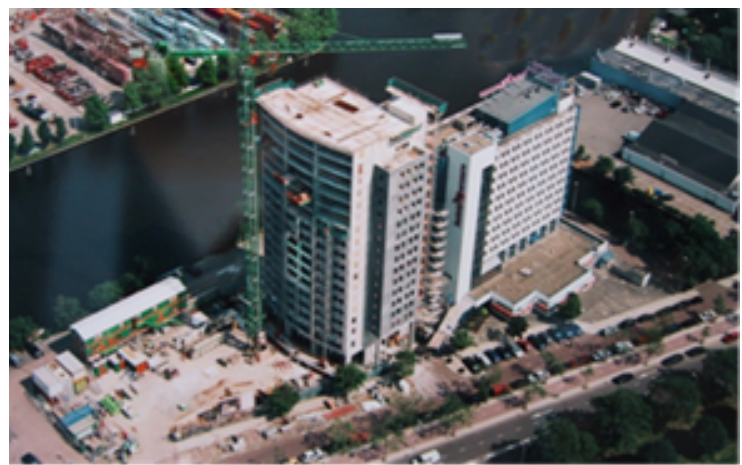

Figure 1: Hotel Mercure a/d Amstel, Amsterdam the Netherlands

The hotel was expanded with a tower building which contains 196 rooms on 18 levels. This result in regard to monitoring a number of items of 196 each was containing 33 items resulting in 6468 parameters.

The database application was considered as a very useful help, especially because of the number of items. The Laptop and the transponder scanner were considered to replaced by smaller and more useful and ergonomically hardware. Based on the experience with introducing new technology on site in the past an important result was the positive 
response of building workers and the willingness to cooperate in a next step.

\subsection{Phase 2}

Components were realized to enable model based ICT in combination with location identification, based on coordinate input. The component enabled to interact with future UPIA device in the next phase.

In this phase the $3 \mathrm{D}$ model provides the data structure and the space is identified in the same 3D model, based on given coordinates. In this stage wireless connection was tested in combination with an ASP and a tablet pc. Coordinates within several spaces were associated with the transponders.

Although the GPRS connection was poor on the highest two levels of the Hotel Mercure building the benefits of the application became clear. The number of users was reduced. Only the foreman used a pocket pc for monitoring. device is successfully used as a monitoring tool, and it appears to improve the opportunity for real-time decision-making on site.

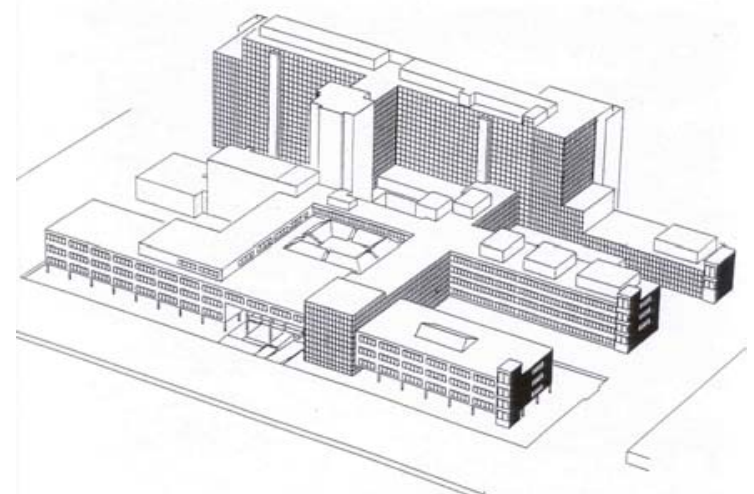

Figure 3: Lucas Andreas Hospital, Amsterdam the Netherlands

\section{CONCLUSIONS AND \\ RECOMMENDATIONS}

The UPIA-device can be a useful, tool for monitoring on site. Especially large and complex building projects provide lots of opportunities because of their number of to be identified items and complex relation

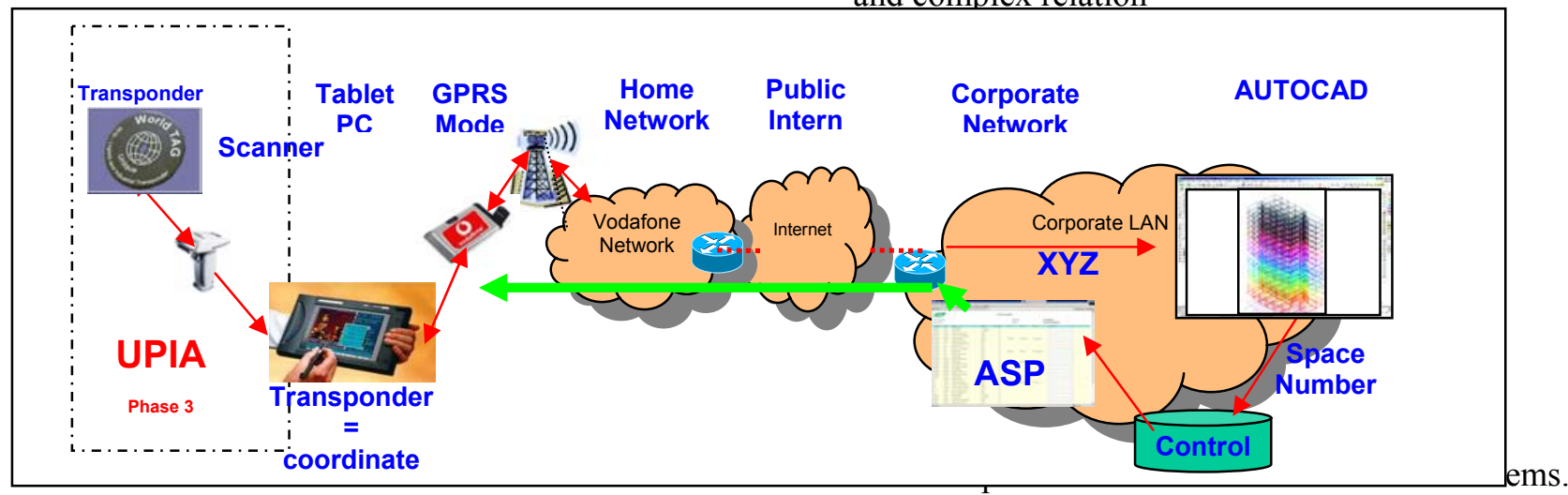

Figure 2: phase 2

\subsection{Phase 3}

The in phase two developed components to enable model based ICT in combination with location identification is further developed to be able to interact with UPI device for positioning.

The 3D model provides the data structure and the space is identified in the same 3D model, based on coordinates given by UPI. The test period at the Lucas Andreas Hospital in Amsterdam is, at the time of writing this article, not finished. However the first results seem very promising. The UPIA-
The UPIA device can possibly be improved by

- benchmark GPRS and other wireless solutions

- implicate use of interface ASP and tablet functionalities [making notes is required, to be saved as pictures]

- GPS precision and availability indoor 


\section{REFERENCES}

[Broekmaat] Broekmaat, Marcel, Bauke de Vries, 2003, Implementation Scenarios for 4D CAD in Pratice, Proceeding at the ISARC 2003.

[Bürgy] Bürgy, Christian, James Garrett, 2002, Situation-aware interface design: an interaction constraints model for finding the right interaction for

mobile and wearable computer systems, Proceeding at the ISARC 2001.

[De Bouw moet om, Op weg naar Feilloos bouwen] De Bouw moet om, Op weg naar Feilloos bouwen, 2000, Stichting Bouwresearch (SBR).

[Fuller] Fuller, Scott, Zhihui Ding, , Anoop Sattineni, 2002, A Case Study: Using the wearable Computer in the construction Industry, Proceeding at the ISARC 2001.

[Half-time: sneller, beter en concurrerender bouwen] Half-time: sneller, beter en concurrerender bouwen, 2000, HBG, TNO-Bouw.

[Quick Scan ICT in de bouw] Quick Scan ICT in de bouw, 2001, Adviesraad Technologiebeleid Bouwnijverheid.

[Saidi] Saidi, Kamel, Carl Has, Nicole Balli, 2002, The value of handheld computers in construction, Proceeding at the ISARC 2001.

[UPIA] UPIA.org 